\title{
Twenty Month Surveillance Infections in Intensive Care Unit of Zagazig University hospitals
}

\author{
${ }^{1}$ Noha M. Abdelsalam, ${ }^{2}$ Sara K. Ahmed and ${ }^{1}$ Ghada M. Khalil \\ ${ }^{1}$ Public Health and Preventive Medicine, Faculty of medicine, Zagazig University, Egypt. \\ ${ }^{2}$ Division of Global Health Protection, U.S. Centers for Disease Control and Prevention, \\ Cairo, Egypt Country Office
}

Received: July, 2018 Accepted: September, 2018

\begin{abstract}
Objective: To report types and rates of healthcare-associated infections (HAIs) as well as pathogen distribution from HAI surveillance system of Zagazig University Hospitals. Method: Active prospective surveillance was conducted from March 2016 through November 2017 in intensive care hospitals (ICUs) in Zagazig university hospitals. Definitions were adapted from the CDC's National Healthcare Safety Network. Data collection was performed by trained healthcare workers in the participating ICUs, and data was recorded on clinical symptoms, radiological and laboratory investigations. A convenience sample of clinical isolates was tested for quality control at a central reference laboratory. Results: Fifteen (15) ICUs from 7 hospitals collected 106,028 patient-days of surveillance data. Of 290 HAIs identified, $56.6 \% \%$ were bloodstream infections followed by urinary tract infection $32.4 \%$. The highest rate of device-associated infections was reported for central lineassociated Blood stream infection (3.39 CLABSIs/1,000 central line-days) followed by ventilator-associated pneumonia (1.13 VAP/1,000 ventilator-days). Out of 280 isolates of ICU acquired organisms, Klebsiella was the most common isolated organism (38.2\%) followed by staphylococcus and E. Coli (11.4\% and 10.4\%). The most common obstacles identified were work overload and lack of cooperation of ICU staff. High levels of satisfaction of surveillance team for surveillance program training course, data collection tools (logbooks and smart devices, and overall usefulness of the program in reducing HAIs) were reported. Conclusions: HAIs have great threat to patient safety in Zagazig University ICUs. Continuation of surveillance activities and implementation of preventive bundles should become a priority for the Infection control team.
\end{abstract}

Keywords: HAI, Surveillance, Incidence, Microorganism, Intensive care units.

Corresponding author: Noha M. Abdelsalam, E-mail: noha_mohamed994@yahoo.com

\section{Introduction}

Surveillance of healthcare-associated infections (HAIs) is a cornerstone in the building of infection control programs. ${ }^{1}$ It provides information on the rates of infection and trends over time that is used to help the implementation of prevention and control strategies and the evaluation of their impact on infection rates. ${ }^{2}$ The World Health Organization (WHO) report on the global burden of HAI in 2011 stated that there is an urgent need to establish reliable systems for HAI surveillance and to collect data on the actual burden on a regular basis. ${ }^{3}$ It has been reported that in hospitals 
with an effective surveillance program for HAIs, infection rate can be reduced by nearly one-third. ${ }^{4}$

Whereas surveillance is an essential part of an effective infection prevention and control program, it often consumes too much time from clinician and infection control team limiting the time available for quality improvement. ${ }^{1}$ Therefore, The Association of Professionals in Infection Control and Epidemiology (APIC) recommends the use of automated surveillance technologies as an essential part of infection prevention and control activities. $^{5}$

Developments in healthcare information technology are rapidly changing the area of HAI surveillance. The electronic availability and incorporation of routine care data in surveillance algorithms enhances the reliability, efficiency and standardization of surveillance practices ${ }^{(6)}$. Zagazig University hospitals include eight hospitals with a total capacity of 1879 beds, 17 intensive care units (ICUs) and 250 ICU beds. It provides a wide variety of secondary and tertiary health care services for a population of around 6 million and 800 thousand inhabitants.

There was no surveillance program in Zagazig university hospitals. In 2016, Zagazig university hospitals have joined for the first time the university hospital surveillance of HAIs and antimicrobial resistance (AMR) in Egypt that was developed with technical and financial support of the U.S. Centers for Disease Control (CDC) and Prevention, Global Disease Detection (GDD) Program in Egypt and the U.S. Agency for International Development in Egypt ${ }^{(7)}$. It is described in this paper the burden of HAIs in intensive care units of Zagazig University hospitals.

The objectives of the study were to describe the burden of HAIs in ICUs of
Zagazig University hospitals, describe the trend of HAIs over time and explore the pathogens contributing to HAIs. Second, to evaluate the satisfaction of the healthcare workers regarding implementation of HAI surveillance.

\section{Method}

Study settings: The HAI surveillance program was done in 15 ICUs; 12 adult, 1 pediatric and 2 neonatal intensive care units (NICUs) in March 2016. This report includes data over 20 months period from March 2016 until end of November 2017. Study design: Active prospective surveillance in intensive care units; the HAI case definitions were adapted from the Centers for Disease Control and Prevention's (CDC's) 2008 National Healthcare Safety Network (NHSN) case definitions ${ }^{(7)}$. The detailed methodology of the HAI surveillance program was described in previous publications ${ }^{(8)}$.

Methods of data collection: Surveillance officers first record all ICUs patient names in a screening logbook then check patient's files for any signs or symptoms suggestive of infection thereafter they document any suspected cases of HAI in the suspect cases logbook and collect data about them with the help of ICU physicians using patient files data (physician progress notes, vital signs, laboratory and radiological findings). After suspecting HAI cases, surveillance officers open smart devices and enter demographic, clinical and laboratory data of suspected cases into the personal digital assistants (PDA). PDAs were used since the beginning of the surveillance program in April 2011 to facilitate data entry. The PDAs were programmed using a decision-based tree helped with classifications of HAIs based on surveillance definitions of CDC. Depending on the information entered, the PDA would direct the surveillance officer 
Table 1: Description of types and number of ICUs, ICU beds, patient-days and healthcare-associated infections (HAI) reported for each type of ICU and pooled mean HAI incidence for each ICU type

\begin{tabular}{|c|c|c|c|c|c|c|c|c|c|c|}
\hline \multirow{2}{*}{$\begin{array}{l}\text { Type of } \\
\text { location }\end{array}$} & \multirow{2}{*}{$\begin{array}{l}\text { No. } \\
\text { ICUs }\end{array}$} & \multirow{2}{*}{$\begin{array}{c}\text { \# HAIs } \\
\text { Reported }\end{array}$} & \multirow{2}{*}{$\begin{array}{c}\text { Patient } \\
\text { days }\end{array}$} & \multirow{2}{*}{$\begin{array}{c}\text { Pooled } \\
\text { mean } \\
\text { incidence } \\
\text { of HAI }\end{array}$} & \multicolumn{2}{|c|}{ Pneumonia } & \multicolumn{2}{|c|}{$\begin{array}{l}\text { Blood -Stream } \\
\text { Infections }\end{array}$} & \multicolumn{2}{|c|}{$\begin{array}{l}\text { Urinary Tract } \\
\text { Infections }\end{array}$} \\
\hline & & & & & No. & $\begin{array}{c}\text { Pooled } \\
\text { mean }\end{array}$ & No. & $\begin{array}{c}\text { Pooled } \\
\text { mean }\end{array}$ & No. & $\begin{array}{c}\text { Pooled } \\
\text { mean }\end{array}$ \\
\hline $\begin{array}{l}\text { Medical } \\
\text { Cardiac } \\
\end{array}$ & 2 & 2 & 12126 & 0.2 & 0 & 0 & 2 & 0.2 & 0 & 0 \\
\hline $\begin{array}{l}\text { Medical } \\
\text { Critical Care }\end{array}$ & 4 & 8 & 42440 & 0.12 & 2 & 0.05 & 2 & 0.05 & 4 & 0.1 \\
\hline Neurological & 2 & 12 & 8135 & 1.5 & 3 & 0.4 & 4 & 0.5 & 5 & 0.6 \\
\hline NICU & 2 & 27 & 14172 & 1.9 & 0 & 0 & 26 & 1.8 & 1 & 0.1 \\
\hline $\begin{array}{l}\text { Pediatric } \\
\text { Medical }\end{array}$ & 1 & 10 & 6683 & 1.5 & 1 & 0.1 & 9 & 1.3 & 0 & 0 \\
\hline Respiratory & 1 & 3 & 3715 & 0.8 & 0 & 0 & 2 & 0.5 & 1 & 0.3 \\
\hline $\begin{array}{l}\text { Surgical } \\
\text { Cardiothoracic }\end{array}$ & 1 & 1 & 2399 & 0.4 & 0 & 0 & 1 & 0.4 & 0 & 0 \\
\hline $\begin{array}{l}\text { Surgical } \\
\text { Critical Care }\end{array}$ & 1 & 126 & 8906 & 14.1 & 10 & 1.1 & 61 & 6.8 & 55 & 6.2 \\
\hline Trauma & 1 & 101 & 7452 & 13.6 & 16 & 2.1 & 57 & 7.6 & 28 & 3.8 \\
\hline Total & 15 & 290 & 106028 & & $32(11.0 \%)$ & & $164(56.6 \%)$ & & $94(32.4 \%)$ & \\
\hline
\end{tabular}

Table 2: Incidence of device- associated infections by type of location, 1 March 2016 - 30 November 2017 (Rates calculated as DAIs /1000 device days)

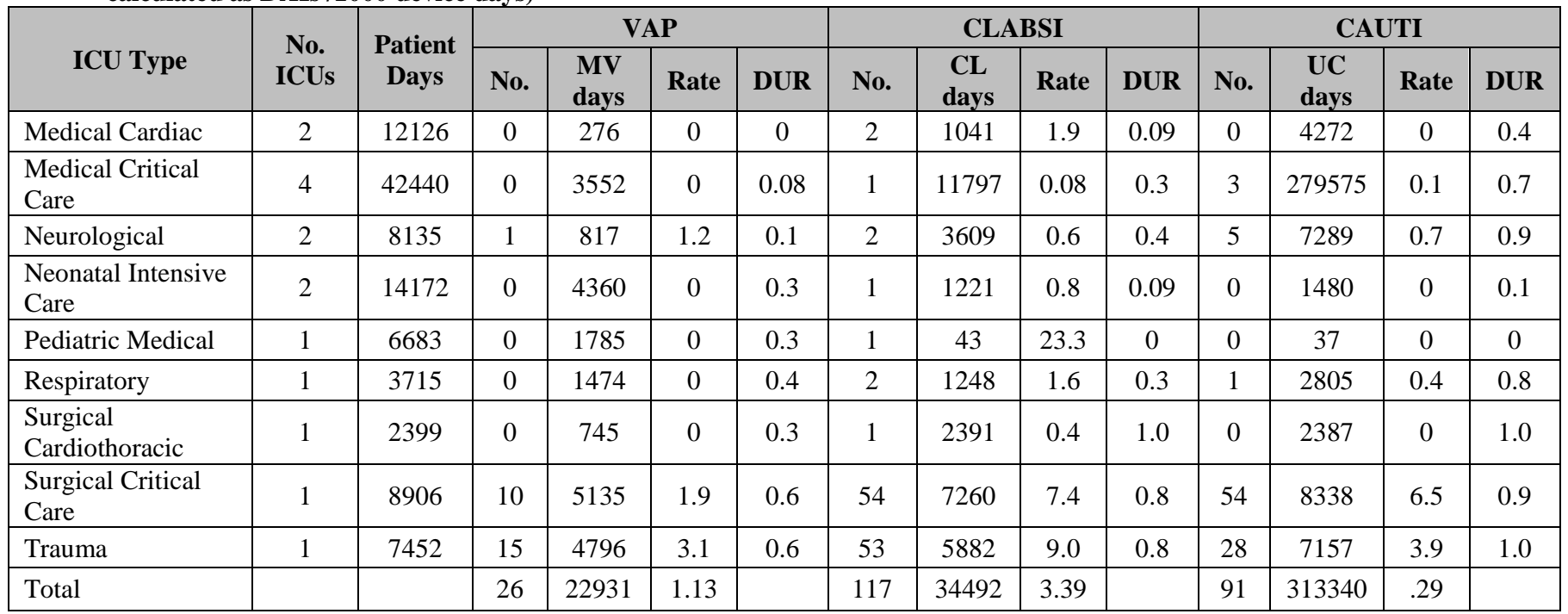

VAP, Ventilator-associated pneumonia. CLABSI, Central line-associated bloodstream infection; CAUTI, Catheter-associated urinary tract infection; $M V$, Mechanical Ventilation; CL,Central Line;UC, Urinary Catheter;DUR, Device Utilization Ratio

to the relevant section. Device days and patient days are collected and recorded in order to be used as denominators for calculation incidence rates of intensive care unit-acquired infections and device associated infections. Surveillance officers deliver the smart devices weekly to data managers and infection control teams to upload and send PDA data electronically to CDC through the Web and automated reports are generated.

Microbiology lab procedures

Pathogens causing HAIs are identified by the hospital microbiology laboratory facilities. Isolates are inoculated as a pure colony onto vials containing trypticase soya broth and sent to the CDC laboratory 
on a monthly basis for confirmatory testing.

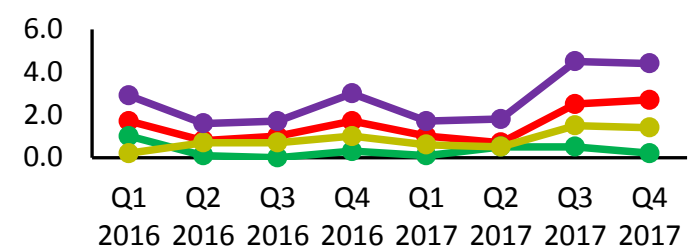

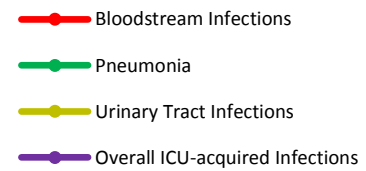

Fig (1): Trend of ICU acquired infections per 1000 patient days from 1 March 2016 to 30 November 2017

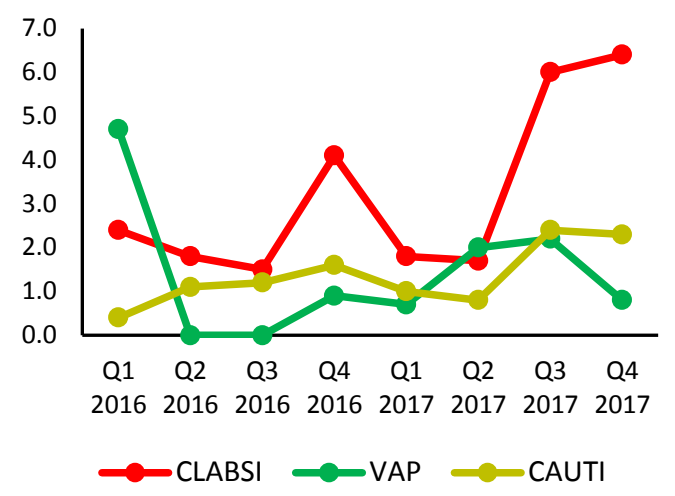

Fig (2): Trend of device associated infections per 1000 device days from 1 March 2016 to 30 November 2017

Table 3: Distribution of pathogens associated with reported ICU-acquired Infections, 01 March 2016 - 30 November 2017

\begin{tabular}{|c|c|c|c|c|c|c|c|c|}
\hline \multirow{2}{*}{ Organism } & \multicolumn{2}{|c|}{$\begin{array}{c}\text { ICU-acquired } \\
\text { Pathogens }\end{array}$} & \multicolumn{2}{c|}{ BSI } & \multicolumn{2}{c|}{ Pneumonia } & \multicolumn{2}{c|}{ UTI } \\
\cline { 2 - 10 } & \multicolumn{2}{|c|}{$\mathbf{n = 2 8 0}$} & \multicolumn{2}{c|}{$\mathbf{n = 1 3 6}$} & \multicolumn{2}{c|}{$\mathbf{n = 2 1}$} & \multicolumn{2}{c|}{ n = 123 } \\
\cline { 2 - 10 } & No. & $\%$ & No. & $\%$ & No. & $\%$ & No. & $\%$ \\
\hline Enterococcus spp. & 1 & 0.4 & 1 & 0.7 & 0 & 0 & 0 & 0 \\
\hline CONS & 11 & 3.9 & 11 & 8.1 & 0 & 0 & 0 & 0 \\
\hline Proteus spp. & 7 & 2.5 & 1 & 0.7 & 2 & 9.5 & 4 & 3.3 \\
\hline S. aureus & 32 & 11.4 & 26 & 19.1 & 1 & 4.8 & 5 & 4.1 \\
\hline Acinetobacter spp. & 28 & 10.0 & 16 & 11.8 & 3 & 14.3 & 9 & 7.3 \\
\hline Candida albicans & 18 & 6.4 & 4 & 2.9 & 0 & 0 & 14 & 11.4 \\
\hline E. coli & 29 & 10.4 & 11 & 8.1 & 3 & 14.3 & 15 & 12.2 \\
\hline Pseudomonas spp. & 29 & 10.4 & 7 & 5.1 & 1 & 4.8 & 21 & 17.1 \\
\hline Klebsiella spp. & 107 & 38.2 & 51 & 37.5 & 11 & 52.4 & 45 & 36.6 \\
\hline Others & 18 & 6.4 & 8 & 5.9 & 0 & 0 & 10 & 8.1 \\
\hline
\end{tabular}




\section{Qualitative survey}

In-depth interviews were conducted with 2 surveillance coordinators, 40 surveillance officers, 2 data managers, 15 ICU managers and the hospital manager. A list of structured open-ended questions was used to identify obstacles confronting the surveillance program and to evaluate the satisfaction regarding the program from the teams' point of view. It includes questions about the training course, data collection tools, data collection process, communication process, data management ,data dissemination and overall usefulness of the program in reducing HAIs .They were asked to rate their perceptions on the usefulness of the program components on a 6-point Likert scale ranging from 'not useful at all' (0) to 'very useful' (5).

Table (4): Evaluation of the program satisfaction from the team' point of view.

\begin{tabular}{|l|c|c|}
\hline Items & Mean \pm SD & Range \\
\hline The training course & $4.33 \pm 0.62$ & $3-5$ \\
\hline Data collection tools & $4.05 \pm 0.54$ & $3-5$ \\
\hline Data collection process & $3.22 \pm 0.43$ & $1-5$ \\
\hline Communication & $3.12 \pm 0.62$ & $1-5$ \\
\hline Data management & $3.44 \pm 0.95$ & $3-5$ \\
Data dissemination & $3.1 \pm 0.2$ & $1-5$ \\
\hline $\begin{array}{l}\text { Overall usefulness of the } \\
\text { program in reducing }\end{array}$ & $4.2 \pm 0.51$ & $4-5$ \\
HAIs & & \\
\hline
\end{tabular}

Statistical management for the qualitative survey:

After data collection, data are coded, entered and analyzed using Statistical Package for Social Science (SPSS) version 19. Frequencies and percent were used to describe Qualitative data. Excel program was used to draw Pareto chart. The frequency of each obstacle confronting the surveillance system was counted. After descending ranking of the different obstacles, the cumulative percentage was calculated. Pareto chart was drawn according to the frequency of each ranked obstacle showing the level of $80 \%$ cumulative percentage as the cutoff point that identifies the corresponding obstacle facing the surveillance program.

\section{Ethical Consideration}

The research protocol was approved by the Ethics Committee of Faculty of Medicine, Zagazig University, Egypt and the reference number is ZU- IRB\#: 4102. The necessary official permission was taken from the hospital manager and the manager of infection control unit of Zagazig University hospitals before the study is carried out.

\section{Results}

Table 1 shows that the incidence rate of HAIs was highest in surgical critical care and in trauma ICU. Blood stream infection was highest in medical critical care, surgical critical care and in trauma ICU representing the highest percentage of total ICU infections which is followed by urinary tract infection in surgical critical care while comes next the ICU acquired pneumonia .

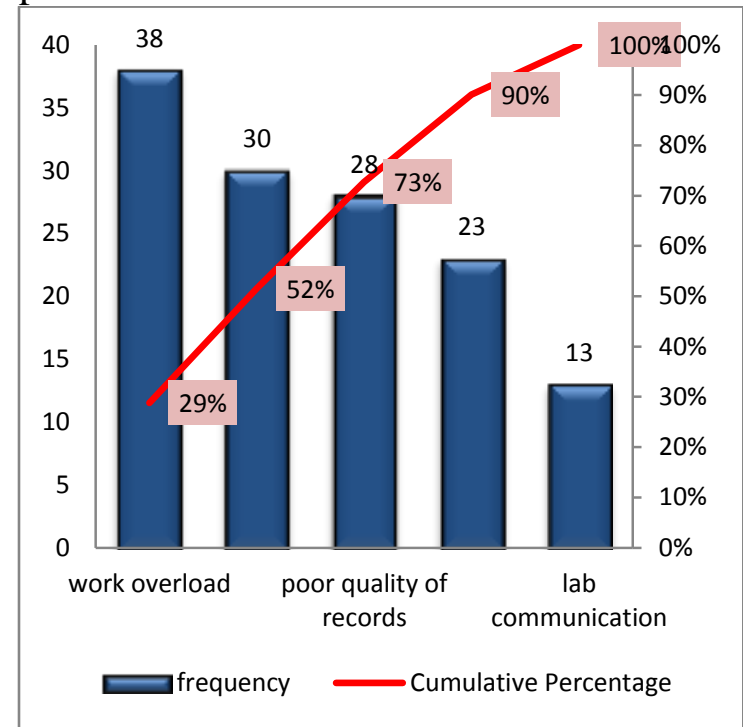

Fig (3): Pareto chart of most obstacles confronting the surveillance program

The highest rate of device-associated infections was reported for central lineassociated Blood stream infection followed by ventilator-associated pneumonia. The incidence of central line associated blood 
stream infections (CLABSIs) per 1000 device days was highest in surgical ICU and in trauma ICU, while it was lowest in medical critical care. The incidence of Ventilator Associated Pneumonia (VAP) was highest in trauma critical ICU. The incidence of Catheter Associated Urinary Tract Infections (CAUTIs) was the highest in surgical critical care (Table 2).

The trend of ICU acquired infections per 1000 patient days from 1 March 2016 to 30 November 2017 and the trend of device associated infections per 1000 device days in the same period are illustrated in figure (1) and figure (2) showing changes in the trend of infections over this period. Most infections have decreased but there was increase in the incidence rates during the third quarter of 2017.

Table 3 shows that Klebsiella was the most common isolated pathogen associated with reported ICU-acquired Infections followed by staph and E.Coli.

Results of this study showed that the higher levels of satisfaction were reported for training course, data collection tools (logbooks and smart devices) and overall usefulness of the program in reducing HAIs (Table 4).

\section{Results of the qualitative survey}

Upon inquiry about the most common obstacles that faced the surveillance program in intensive care units as reported by the surveillance team, the Pareto chart showed that the most frequent vital few obstacles are work overload, lack of cooperation of ICU staff and poor quality of records (Figure 3).

\section{Discussion}

The surveillance program for HAIs in intensive care units was conducted for the first time in Zagazig University hospitals in 15 ICUs. The program showed that surgical critical care and trauma critical care demonstrated the highest incidence rates of HAIs. In addition, these two ICUs showed the highest rates for the most common three types of HAIs namely pneumonia, BSIs, and UTIs. This was most probably due to prolonged length of stay of patients admitted to these 2 ICUs in our institution after surviving multiple trauma or surgical intervention ,further more patients in these 2 ICUs have been exposed to multiple intervention strategies, invasive procedures and high device utilization that make them at high risk of developing HAIs, so ICU staff and infection control team in these ICUs should focus their attention on implementation and maintenance of preventive measures and infection control guidelines to decrease infection rates thus increasing patient safety, quality of care and decreasing mortality rates in ICUs. This finding conforms the findings of Dudeck et al $(2013)^{8}$, where the highest infection rates were in trauma ICUs in the acute care hospitals in the United States, as patients are being at high risk of infection because of multiple surgical procedures, the underlying conditions, the need for mechanical ventilation, repeated blood transfusions and high device utilization rate compared with other ICUs. ${ }^{9}$ Moreover, Askarian et al ( 2012) ${ }^{10}$ stated that infection rates were highest in surgical and medical ICUs.

In this report, BSI was the commonest ICU acquired infection. This might be due to the high utilization ratio of central lines in ICUs, also diagnosis and reporting of BSI and CLABSI by our surveillance officers was still easier than diagnosis and reporting of pneumonia and VAP that remains challenging especially with lack of cooperation from ICUs staffs .So many efforts are needed to increase awareness of ICUs staff about care bundles. Cooperation of ICUs staff is also needed to help surveillance officers in diagnosis and 
reporting of pneumonia and VAP. This figure was higher than that reported by Talaat et al (2016). ${ }^{7}$ Once more, the incidence rate of BSIs in surgical critical care and in trauma ICU was higher than that reported by Talaat et al $(2016)^{7}$ and the Annual Epidemiological Report of the European Centre for Disease Prevention and Control (2016). ${ }^{11}$ While on the other hand, the incidence of ICU acquired pneumonia was lower as compared with them. The incidence of CLABSIs per 1000 device days was higher than that reported by Talaat et al $(2016)^{7}$ in adult ICUs and Rasslan et al (2012) ${ }^{12}$ in pediatric intensive care units of hospitals in Egypt but it is much lower than that reported by Rasslan et al $(2012)^{12}$ in adult ICUs. This difference may be due to variations in ICU type, Variations in resources and funds supporting infection control program and health care workers' compliance to infection control guidelines.

The incidence rate of VAP in this report in trauma critical ICU was little lower than that found by Kohlenberg et al (2010) ${ }^{13}$ in Germany and Talaat et al (2016) ${ }^{7}$ in Egypt but it is much lower than reported by Othman and Abdelazim (2017) ${ }^{14}$ in Saudi Arabia which might be due to underestimation of VAP in hospitals of Egypt .

In hospitals of this study, CAUTIs incidence rate was higher than the figure reported in the Annual Epidemiological Report, 2016 of the European Centre for Disease Prevention and Control ${ }^{11}$, and Talaat et al (2016). ${ }^{7}$ This high rate of CAUTIs was most probably due to nonadherence of healthcare workers in studied ICUs to Bundle for preventing infection when inserting and maintaining a urinary catheter, infection control team should focus their attention and efforts on increasing awareness and providing knowledge about Bundles for preventing
CAUTIs when inserting and maintaining a urinary catheter.

Klebsiella, staph and E.Coli were the most predominant isolated species in intensive care units in this report. This might be due to low compliance of healthcare providers to hand hygiene measures also environmental contamination might be another factor. This mimic multiple surveillance studies in Europe, USA, Egypt and Saudi Arabia. 7,14,15,16

Results of this report showed high levels of satisfaction of surveillance team for surveillance program training course, data collection tools (logbooks and smart devices, and overall usefulness of the program in reducing HAIs .Use of smart devices set up with simple programs for surveillance made data collection and analysis more easy and accurate that satisfy the surveillance team. This conforms the finding of Klompas and Platt $(2007)^{17}$ Stevens et al $(2014)^{18}$ and ElFeky et al (2016) ${ }^{19}$ who recommended use of automated surveillance for easy and accurate data collection and analysis and taking actions upon them.

The most common obstacles that face the surveillance program in intensive care units are work overload, lack of cooperation of ICU staff and poor quality of records; many efforts are needed to overcome these obstacles and to increase the awareness of ICUs staff on the importance of surveillance program and its usefulness of the program in reducing HAIs . These obstacles were the same obstacles suggested by some other researchers. $^{7}$

Despite the challenges, Zagazig university hospitals are now a part of a national HAI Surveillance program and having efficient surveillance team that can collect data and generate HAI rates in intensive care units to monitor infection control program, identify defects and try to solve problems. 
However many studies are still needed to test the validity of the automated surveillance program and many efforts still needed to calculate the accurate rates depending on collecting accurate data.

\section{Conclusion}

This report describes the automated surveillance program for HAIs in intensive care units conducted for the first time in our institution. The automated surveillance gave an effective and accurate idea about the burden of HAIs in ICUs of Zagazig University hospitals, describe the trend of HAIs over time and explore the pathogens contributing to HAIs. There are some obstacles confronting the implementation of the surveillance program which are work overload, lack of cooperation of ICU staff and poor quality of records. Many studies are still needed to test the validity of the automated surveillance program and many efforts still needed to calculate the accurate rates depending on collecting accurate data.

\section{Acknowledgments}

We would like to thank the Centers for Disease Control (CDC) and Prevention, Global Disease Detection (GDD) Program in Egypt and the U.S, infection control unit of Zagazig university hospitals all healthcare providers in intensive care units and the surveillance team for their cooperation, also the hospital management for their support in achieving our work.

\section{Conflict of Interests}

None declared.

\section{References:}

1. Reilly JS, McCoubrey J, Cole S, Khan A, Cook B (2015): Integrating intensive care unit (ICU) surveillance into an ICU clinical care electronic system. Journal of Hospital Infection ; 89: 271-275.

2. National Infection Control Guidelines 2016 Draft for Consultation (2016): Available at https://www.moh.gov.sg/content/
moh_web/home/Publications/guidelines/infecti on_control_guidelines/national-infection-

control-guidelines--2016-draft-for consultati /_jcr_content/entryContent/download/file.res/

National\%20Infection\%20Control\%20Guideli nes $\% 20-\% 202016 \%$ 20Draft\%20for\%20Consultation.pdf.

3. Marchetti A, Rossiter R (2013): Economic burden of healthcare-associated infection in US acute care hospitals: societal perspective. J Med Econ ;16 (12): 1399-404.

4. Dasgupta S, Das S, Chawan NS, Hazra A (2015): Nosocomial infections in the intensive care unit: Incidence, risk factors, outcome and associated pathogens in a public tertiary teaching hospital of Eastern India. Indian Journal of Critical Care Medicine: Peerreviewed, Official Publication of Indian Society of Critical Care Medicine ;19 (1):1420. doi:10.4103/0972-5229.148633.

5. Greene LR , Cain TA, Khoury R, Krystofiak SP, Patrick M, Streed S(2009): APIC Position Paper: The Importance of Surveillance Technologies in the Prevention of Healthcare-Associated Infections (HAIs). Avaiable at http://www.apic.org/Resource_/TinyMceFileM anager/Position_Statements/Surveillance-

Technologies-position-paper-2009.pdf

6. Sips ME, Bonten MJ, van Mourik MS (2017): Automated surveillance of healthcareassociated infections: state of the art. Curr Opin Infect Dis ; 30(4):425-431. Available at https://www.ncbi.nlm.nih.gov/pubmed/285050 27

7. Talaat M, El-Shokry M, El-Kholy J ,Ismail Gh, Kotb S, Hafez S, Attia E, Lessa F(2016): National surveillance of health care-associated infections in Egypt: Developing a sustainable program in a resource-limited country. American Journal of Infection Control ; 44 : 1296-301.

8. Dudeck MA,Weiner LM, Allen-Bridson K, Malpiedi PL, Peterson KD, Pollock DA, et al (2013): National Healthcare Safety Network (NHSN) report, data summary for 2012, Device-associated module. Am J Infect Control ;41:1148-66.

9. Richards M, Thursky K, Buising K (2003):

Epidemiology, prevalence, and sites of 
infections in intensive care units. Semin Respir Crit Care Med ;24:3-22.

10. Askarian M, Yadollahi M, Assadian O (2012): Point prevalence and risk factors of hospital acquired infections in a cluster of university-affiliated hospitals in Shiraz, Iran. Journal Of Infection and Public Health ;5: $169-176$.

11.European Centre for Disease Prevention and Control (2016): Annual Epidemiological Report 2016 - Healthcare-associated infections acquired in intensive care units. Available from https://ecdc.europa.eu/en/publicationsdata/healthcare-associated-infections-acquiredintensive-care-units-annual.

12. Rasslan O , Seliem Z, Ghazi I, Abd El Sabour M, El Kholy A, Sadeq F, Kalil M, Abdel-Aziz D, Sharaf H, Saeed A, Agha H, Zein El-Abdeen S, Gafarey M, El Tantawyb A, Fouad L, Abel-Haleim M,Muhamed T, Saeed H, Rosenthal V (2012): Deviceassociated infection rates in adult and pediatric intensive care units of hospitals in Egypt. International Nosocomial Infection Control Consortium (INICC) findings. Journal of Infection and Public Health ; 5: 394-402.

13. Kohlenberg A, Schwab F, Behnke M, Geffers C, Gastmeier P (2010): Pneumonia associated with invasive and noninvasive ventilation: an analysis of the German nosocomial infection surveillance system database. Intensive Care Med ;36:971-8.

14. Othman A, Abdelazim M (2017): Ventilator-associated pneumonia in adult intensive care unit prevalence and complications. Egypt J Crit Care Med.Available from https://www.researchgate.net/publication/3179 70465_Ventilator

associated_pneumonia_in_adult_intensive_car e_unit_prevalence_and_complications [accessed Jun 24 2018].

15. Sievert DM, Ricks P, Edwards JR, Schneider A, Patel J, Srinivasan A, et al (2013): Antimicrobial-resistant pathogens associated with healthcare-associated infections: summary of data reported to the national healthcare safety network at the centers for disease control and prevention, 2009 2010. Infect Control Hosp Epidemiol ;34:1-14.
16. Khan MA (2012): Bacterial spectrum and susceptibility patterns of pathogens in ICU and IMCU of a secondary care hospital in Kingdom of Saudi Arabia. Int J Path ;10:6470.

17. Klompas M, Yokoe DS (2009): Automated surveillance of health careassociated infections. Clin Infect Dis ;48:1268-1275.

18. Stevens JP, Silva G, Gillis J, Novack V, Talmor D, Klompas M, Howell MD (2014): Automated surveillance for ventilatorassociated events. Chest ;146(6):1612-1618. Available from https://www.ncbi.nlm.nih.gov/pubmed/254513 50.

19. El-Feky E, Saleh D, El-Kholy J, Sayed A, Mansi Y, Hashem M (2016): Use of personal digital assistants to detect healthcareassociated infections in a neonatal intensive care unit in Egypt. J Infect Dev Ctries; 10(11) 